

\section{DISCLAIMER}

This report was prepared as an account of work sponsored by an agency of the United States Government. Neither the United States Government nor any agency Thereof, nor any of their employees, makes any warranty, express or implied, or assumes any legal liability or responsibility for the accuracy, completeness, or usefulness of any information, apparatus, product, or process disclosed, or represents that its use would not infringe privately owned rights. Reference herein to any specific commercial product, process, or service by trade name, trademark, manufacturer, or otherwise does not necessarily constitute or imply its endorsement, recommendation, or favoring by the United States Government or any agency thereof. The views and opinions of authors expressed herein do not necessarily state or reflect those of the United States Government or any agency thereof. 


\section{DISCLAIMER}

Portions of this document may be illegible in electronic image products. Images are produced from the best available original document. 


\section{CALCULATION OF BRINE PROPERTIES}

\section{ABSTRACT}

Simple analytical expressions are presented for estimating geothermal brine thermophysical properties above $80^{\circ} \mathrm{F}$ and for salt contents between 5 and 25 percent by weight.

Linear regression by the method of least squares is used to curve-fit saturated liquid enthalpy and density data on simulated brines. Brine saturation pressure is calculated as a percentage of the pure water saturation pressure at the same temperature. Saturated liquid brine entropy is determined from an approximation to the differential equation for entropy change using the previously determined relationships for the other property values needed.

Brine vapor properties are assumed equal to steam properties at the same temperature and pressure and are obtained from the ASME equation-of-state for pure water. 


\title{
CALCULATION OF BRINE PROPERTIES
}

\author{
by \\ Gerald L. Dittman
}

\section{Introduction}

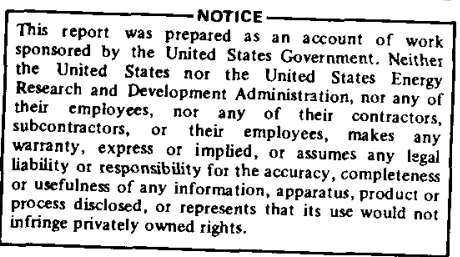

Simplified analytical expressions are currently needed to provide estimates of the equation of state for geothermal brines. These expressions can then be incorporated into various numerical codes developed for the Total Flow program that require predictions of Salton Sea brine thermophysical properties as functions of temperature and salt content (1).

Researchers at the Denver Research Institute - University of Denver have measured thermophysical properties in the laboratory using water solutions with varying weight percent solids with a constant concentration of potassium, calcium, and sodium chlorides in the ratio $1.00: 1.95: 3.55$, respectively, to sirlulate Salton Sea geothermal brines (2). Haas has produced a complex mathematical model for predicting, with high precision, the liquid saturation pressure and density corresponding to a saturation temperature for brine of constant composition using available data for vapor-saturated sodium chloride-water solutions (3). Daley, et al, measured the enthalpy of several concentrates of natural seawater. From this data they developed a complex and precise mathematical expression for predicting the enthalpy which was then used in other analytical formulations to calculate entropy and specific heat as a function of temperature (to $400^{\circ} \mathrm{F}$ ) for the several salinities chosen (4). Grens has reviewed some of these, and additional data, and suggested the use of an approximation for predicting brine saturated liquid enthalpy based on the pure water value at the appropriate saturation temperature and the averaged heat capacity of the dissolved salts

Potter and Haas have reviewed the published 1 iterature for data on the thermophysical properties of geotehrmal brines, simulated brines and seawater solutions of different salinities at various temperatures. Interpretation of this body of information coupled with additional experimental work of their own has led to a theoretical understanding and basis for accurately predicting geothermal brine physical and thermodynamic properties as a function of composition and temperature (6). 
Comparisons between the measured or predicted properties of the simulated brines and actual Salton Sea brines is not possible at present since very little experimental data exists in the literature concerning the thermodynamic properties of the geothermal fluids at compositions and temperatures of interest. Complex and precise mathematical expressions for predicting geothermal brine properties based on simulations of the fluid do not seem warranted for now. Simple mathematical formulations are desired until experimental data is available. The approach used here is to curve-fit some of the data for the simulated brines presented in the references, using linear regression by the method of least squares (7). The brine saturated vapor properties are assumed to be equal to the pure water values given by the ASME equation of state at the appropriate pressure and temperature (8). It is also assumed that properties at other salt concentrations can be obtained by interpolation between the values used here.

Development of the expressions for brine saturation pressure, 1 iquid and vapor density, enthalpy and entropy is explained in the following pages. A subsequent discussion compares the results of these expressions with the results produced in the cited references.

Nomenclature and Units

$\mathrm{T}, \mathrm{T} 1, \mathrm{~T} 2$ temperatures, ${ }^{\circ} \mathrm{F}$

Pure Water Properties

$\operatorname{PSAT}(T)$, saturated vapor pressure at $T$, PSIA

$S G(T)$, saturated vapor entropy at $T, B T U / L B M-{ }^{\circ} R$

$\operatorname{SVG}(T)$, specific volume of saturated water vapor at $T, F T^{3} / L B M$

\section{Brine Properties}

$H B(T)$, saturated liquid enthalpy at $T$ and $X_{S}$, BTU/LBM

$H G B(T)$, vapor enthalpy at $T$ and $\operatorname{PSATB}(T), B T U / L B M$

$\operatorname{PSATB}(T)$, saturated vapor pressure at $T$ and $X_{S}$, PSIA

$\operatorname{RHOB}(T)$, liquid density at $T$ and $X s, L B M / F T^{3}$

$\operatorname{RHOGB}(T)$, vapor density at $T$ and $\operatorname{PSATB}(T), \mathrm{LBM}_{\mathrm{F}} \mathrm{FT}^{3}$ 
$\mathrm{SB}(T)$, saturated liquid entropy at $T$ and $X S$, BTU/LBM- ${ }^{\circ} R$

$\operatorname{SGB}(T)$, vapor entropy at $T$ and $\operatorname{PSATB}(T)$, BTU/LBM- ${ }^{\circ} R$

$X_{s}$, salt content, weight percent

$a_{1}$, averaged ratio of brine and pure water saturation pressures at $T$ and $X_{s}$

$a_{2}, a_{3}, a_{4}, a_{5}$, regression coefficients

$r$, regression analysis coefficient of determination

Results

1. Brine Saturation Pressure, PSATB(T)

Using the data in Reference 3, Table $A 1$ in the Appendix, the ratio of brine and pure water saturation pressures corresponding to the given saturation temperature $\left(230^{\circ} \mathrm{F}\right.$ to $\left.626^{\circ} \mathrm{F}\right)$ was formed for each weight percent salt. An average value for this ratio over the temperature range was used for the coefficient, $a_{1}$. The brine saturation pressure is then determined from the results shown in Table 1 .

\section{TRRE 1}

Brine Saturated Pressure Coefficients

$$
\operatorname{PSATE}(T)=a_{1} \times \operatorname{PSAT}(T)
$$

$\underline{x_{s}, W t . \text { Percent }}$

$$
5
$$

10

15

20

25

$a_{1}$
.969
.934
.894
.847
.794

Figure 1 is a plot of brine saturation pressure and temperature with salt content as a parameter. 





2. Brine Liquid Density, RHOB(T)

A linear relationship of the form $\operatorname{RHOB}(T)=\mathrm{a}_{2} \times T+\mathrm{a}_{3}$ is assumed and a regression analysis was performed using the data from Reference 3. The calculation is shown in the Appendix and tabulated in Table A2. The linear relationship appears to be a good fit to the data since the value of the coefficient of determination is very close to 1 . Brine density is calculated from the results shown in Table 2 .

\section{TABLE 2}

Brine Liquid Density Coefficients

$$
\operatorname{RHOB}(T)=a_{2} \times T+a_{3}
$$

$x_{s}$, wt. Percent

5

10

15

20

25

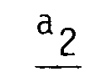

$-.043$

$-.039$

$-.035$

$-.032$

$-.030$



72.60

73.72

74.86

76.21

77.85

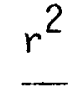

.9793

.9853

.9921

.9977

Figure 2 is a plot of brine liquid density and temperature with salt content as a parameter. The density relationship for pure water is shown for comparison. The slopes of the brine curves are the same as the slope of the pure water curve between about $250^{\circ} \mathrm{F}$ and $575^{\circ} \mathrm{F}$. Above and below these values, pure water density departs significantly from a linear variation with temperature and the assumed relationship for the brine density variation is not accurate. The error between the actual pure water density value and the extrapolation of the slope back to $100^{\circ} \mathrm{F}$ is approximately $6 \%$. 


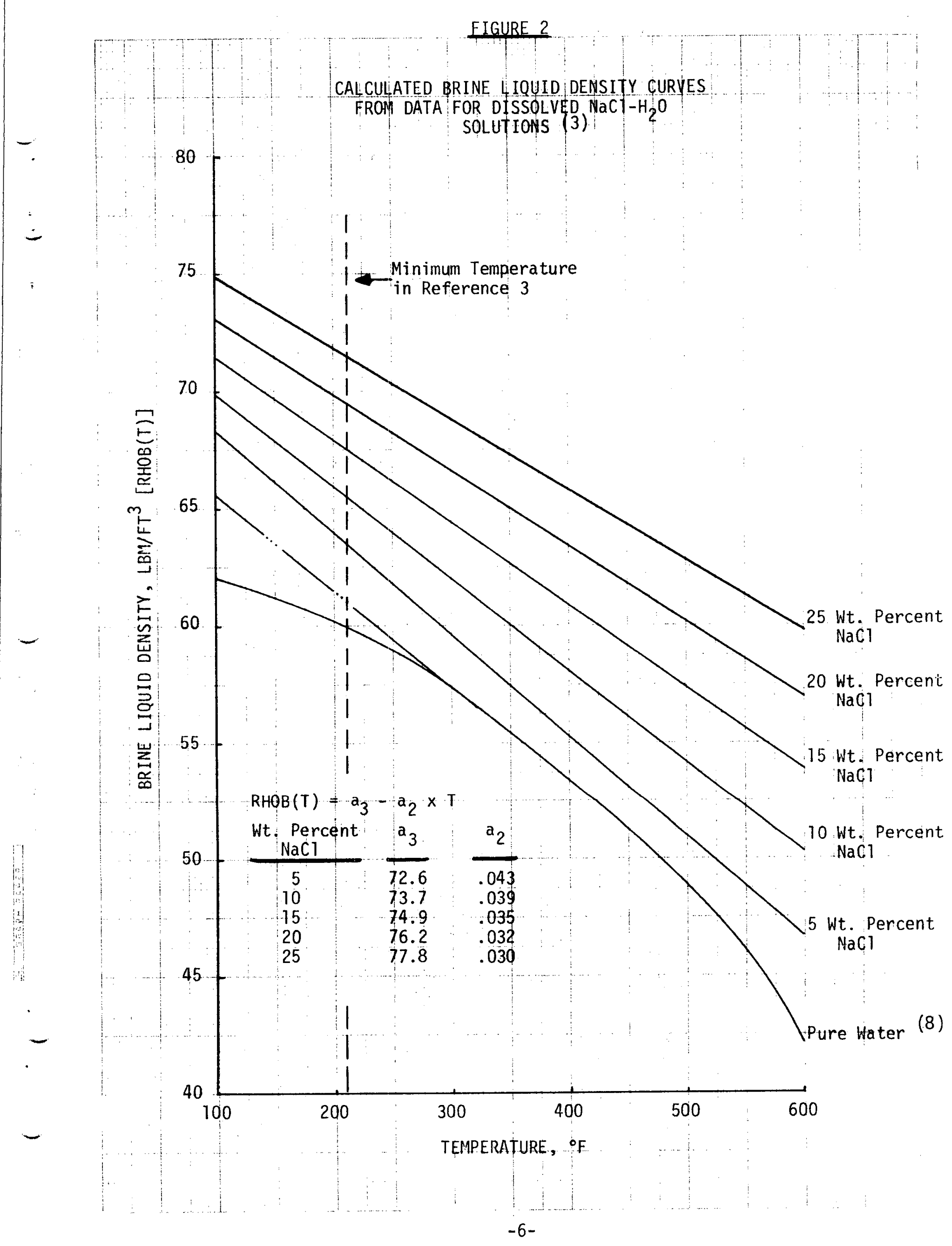


3. Brine Vapor Density, RHOGB(T)

The brine vapor density is determined from an isothermal perfect gas expansion from $\operatorname{PSAT}(T)$ to $\operatorname{PSATB}(T)$ :

$$
\begin{aligned}
& \operatorname{RHOGB}(T)=\frac{\operatorname{PSATB}(T)}{\operatorname{PSAT}(T)} \times \frac{1}{\operatorname{SVG}(T)} \\
& \operatorname{RHOGB}(T)=\frac{a_{1}}{\operatorname{SVG}(T)}, \begin{array}{l}
\text { where SVG }(T) \text { is determined from the pure } \\
\text { water equation-of-state }
\end{array}
\end{aligned}
$$

4. Brine Saturated Liquid Enthalpy, $H B(T)$

A power curve relationship of the form, $H B(T)=a_{4}(T)^{a_{5}}$, is assumed and a linear regression analysis was performed using the data from Reference 4. The analysis is shown in the Appendix and is tabulated in Table A3. The power law relationship appears to be a good fit to the data because the coefficient of determination is again close to 1 . Saturated brine enthalpy is calculated using the coefficients shown in Table 3.

\section{TABLE 3}

Saturated Brine Enthalpy Coefficients

$$
H B(T)=a_{4}(T) a_{5}
$$

\begin{tabular}{cccc}
$\mathrm{X}_{\mathrm{s}}$, Wt. Percent & $\frac{\mathrm{a}_{4}}{\mathrm{a}_{5}}$ & $\frac{r^{2}}{2}$ & - \\
\hline 5 & .275 & 1.1996 & .9985 \\
10 & .304 & 1.1746 & .9990 \\
15 & .340 & 1.1480 & .9992 \\
20 & .368 & 1.1274 & .9994 \\
25 & .396 & 1.1087 & .9995
\end{tabular}


Figure 3 is a plot of brine saturated liquid enthalpy and temperature with salt content as a parameter. Since the enthalpy measurements were not performed abave $400^{\circ} \mathrm{F}$, the brine enthalpy values above this temperature are extrapolated using the equations generated.

5. Brine Vapor Enthalpy, $H G B(T)$

The brine vapor is superheated compared to pure water because the brine saturation pressure is less than the pure water saturation pressure at temperature, T. The value is determined from the pure water equation of state at temperature, $T$ and pressure, $\operatorname{PSATB}(T)$.

6. Brine Liquid Entropy, SB(T)

From the thermodynamic relationship, $d s=\frac{1}{T}\left(d h-\frac{d p}{\rho}\right.$, an approximation for the entropy change between temperature $\mathrm{T} 1$ and $\mathrm{T} 2$ is given by:

$$
S B(T 2)-S B(T 1) \cong \frac{[H B(T 2)-H B(T 1)]-\left[\frac{\operatorname{PSATB}(T 2)-\operatorname{PSATB}(T 1)}{\left.\frac{R H O B(T 2)+R H O B(T 1)}{2}\right] \frac{(12)^{2}}{\mathrm{~J}}}\right.}{(\bar{T}=459.67)},
$$

which can be reduced to:

$$
S B(T 2)-S B(T 1) \cong \frac{a_{4}\left[(T 2)^{a} 5-(T 1)^{a} 5\right]-\frac{\alpha[\operatorname{PSAT}(T 2)-\operatorname{PSAT}(T 1)]}{1-B \bar{T}}}{(\bar{T}+459.67)},
$$

where,

$$
\begin{aligned}
& \alpha=\frac{(12)^{2}}{\mathrm{~J}} \cdot \frac{\mathrm{a}_{1}}{\mathrm{a}_{3}}, \frac{\mathrm{BTU}-\mathrm{IN}^{2}}{\mathrm{FT}^{3}-\mathrm{LBF}} \\
& B=\frac{\mathrm{a}_{2}}{\mathrm{a}_{3}} \\
& J=778, \frac{\mathrm{FT}-\mathrm{LBF}}{\mathrm{BTU}} \\
& T=\frac{\mathrm{T} 1+\mathrm{T} 2}{2},{ }^{\circ} \mathrm{F}
\end{aligned}
$$




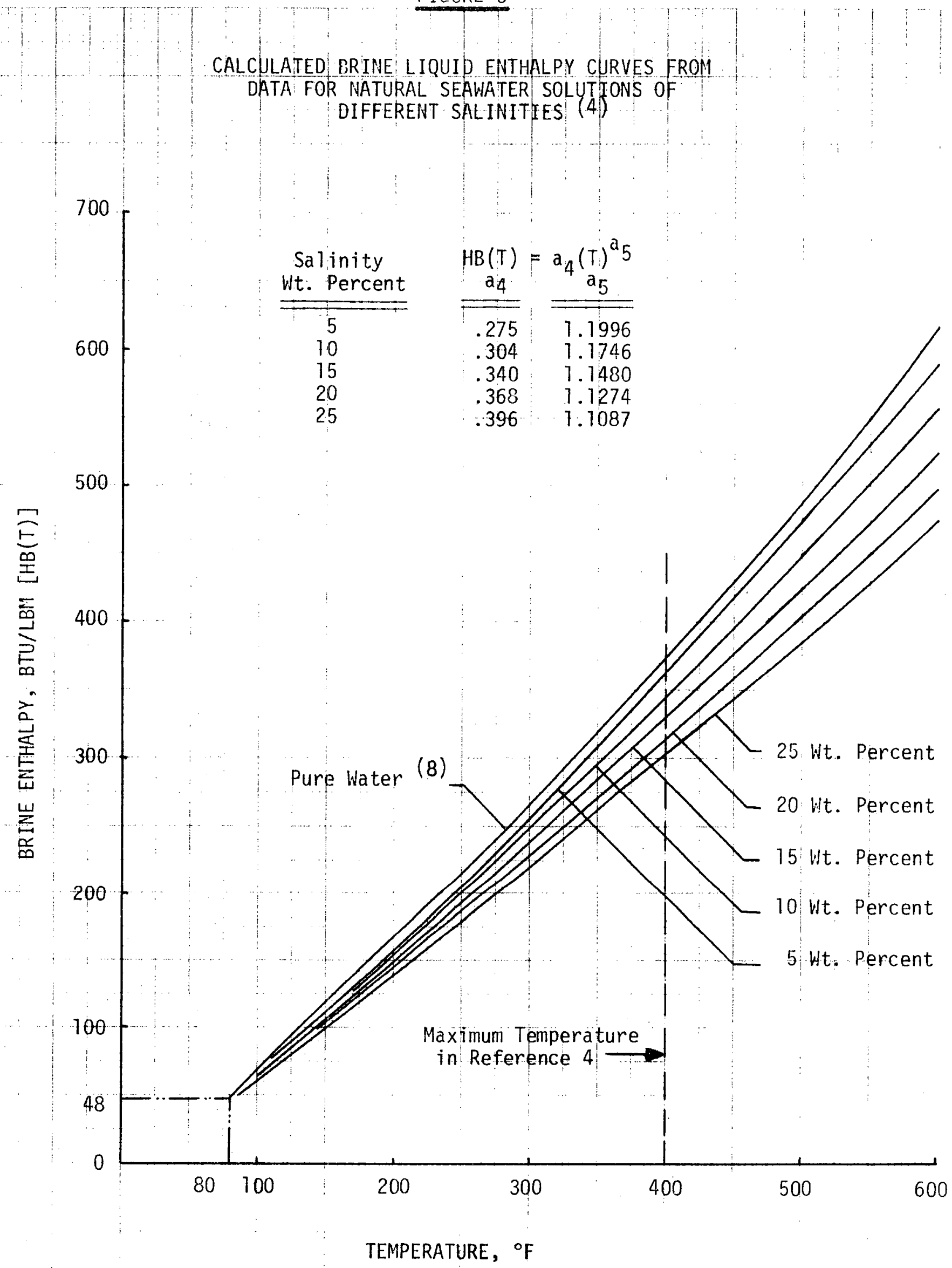


The relationship is accurate for small temperature differences.

Using the entropy predictions in Reference 4 at $80^{\circ} \mathrm{F}$ as a starting point, the brine liquid entropy for the different compositions was calculated and is tabulated in the Appendix as Table A4. The results are graphed in Figure 4 as a function of temperature with weight percent salt as a parameter.

\section{Brine Vapor Entropy, $S G B(T)$}

The brine entropy of vaporization is equal to the enthalpy of vaporization divided by the absolute temperature.

$$
\operatorname{SGB}(T)=S B(T)+\frac{H G B(T)-H B(T)}{(T+459.67)}
$$

and can be calculated using the previously determined thermodynamic properties.

\section{Discussion of Results}

A comparison of the brine properties for several constant salt percentages and selected temperatures as tabulated in the references cited and predicted here is shown in Table 4 below. The assumed constant ratio relationship between brine and pure water saturation pressures (with a different value of the ratio for each different salt content) appears adequate to predict the brine saturation pressure as a function of temperature for the salt percentages considered. Excellent agreement between the pressure predictions (up to $400^{\circ} \mathrm{F}$ maximum) from References 2 and 3 is also shown.

Very good agreement between the linear curve fit and source data (Reference 3) is shown for liquid density. However, since the brine density variation with temperature really follows the shape of the pure water density curve, the 1 inear assumption is not accurate and leads to brine density predictions that are high by about six percent at $100^{\circ} \mathrm{F}$ and $600^{\circ} \mathrm{F}$. Again, excellent agreement exists between the two references (up to $400^{\circ} \mathrm{F}$ ) for the density predictions at the salinities listed. The power law relationship between saturated brine enthalpy and temperature at the salinities considered is in good agreement with the source data (Reference 4). The DRI measurements, however, appear to be consistently 


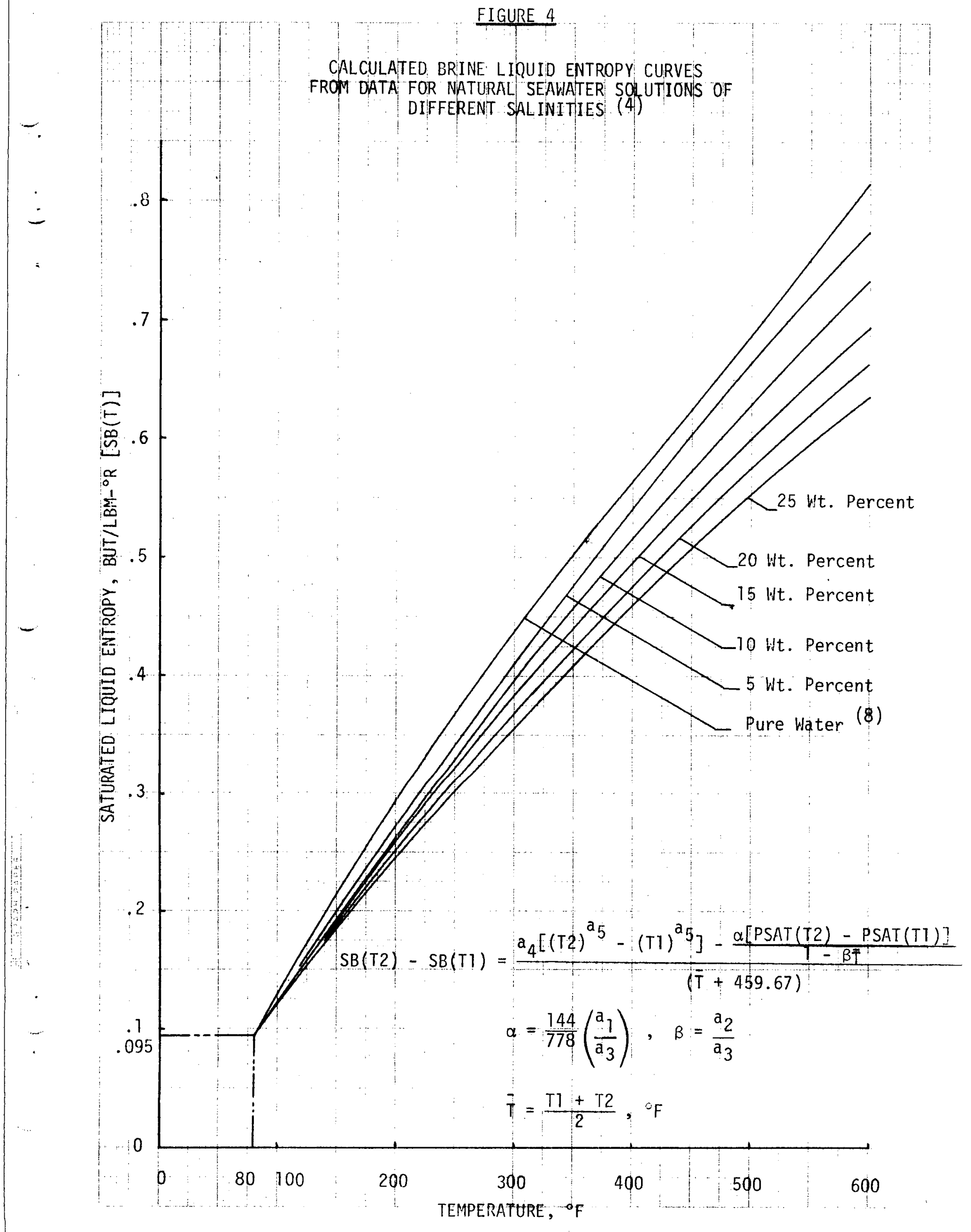


lower than the Daley, et al, measurements on seawater concentrates. On the other hand, the technique suggested by Grens predicts lower enthalpy at the lower salt content but higher enthalpy at the upper salt percentages. The relationship derived here will be considered adequate until experimental data is available for comparison.

Comparison of the values of saturated brine entropy calculated in Reference 4 and here for the several salinities considered and up to $400^{\circ} \mathrm{F}$, shows reasonable agreement between results.

Summary

Simple mathematical expressions for estimating the brine properties of density, saturation pressure, enthalpy and entropy have been generated. They are based on existing data for constant composition water solutions of primarily sodium chloride and for several concentrates of natural seawater. Comparison of the properties predicted by the relationships employed here and the data used to generate the expressions, indicates very good agreement (less than 6 percent difference) for the temperatures and salinities considered.

More complex and precise mathematical expressions have been developed in the references cited for properties of the simulated brines and could be used in numerical applications. However, until data on actual Salton Sea brines are available and comparisons between predictive techniques made, use of the more simple expressions seem adequate. 
TABLE 4

COMPARISON OF BRINE PROPERTIES AT SEVERAL SALT PERCENTAGES

AND SELECTED TEMPERATURES

\begin{tabular}{|c|c|c|c|c|c|c|c|c|c|c|c|c|c|}
\hline \multirow{2}{*}{$\begin{array}{l}\text { Weight } \\
\text { Percent } \\
\text { Salt }\end{array}$} & \multirow{2}{*}{${ }^{\mathrm{T}} \mathrm{F}}$, & \multicolumn{3}{|c|}{ Saturation Pressure, PSIA } & \multicolumn{3}{|c|}{ Liquid Density, LBM/FT ${ }^{3}$} & \multicolumn{4}{|c|}{ Sat. Liquid Enthalpy, BTU/LBM } & \multicolumn{2}{|c|}{$\begin{array}{l}\text { Sat. Liquid Entropy } \\
\text { BTU/LBM- }{ }^{\circ} \\
\end{array}$} \\
\hline & & Ref. 2 & Ref. 3 & $\operatorname{PSATB}(T)$ & Ref. 2 & Ref. 3 & RHOB (T) & Ref. 2 & Ref. 4 & Ref. 5 & $H B(T)$ & Ref. 4 & $S B(T)$ \\
\hline \multirow{3}{*}{5} & 200 & 11.3 & 11.6 & 11.2 & 62.2 & 62.3 & 64.0 & 154 & 162 & 161 & 158 & .2831 & .2712 \\
\hline & 400 & 241.7 & 240.8 & 239.6 & 56.2 & 56.1 & 55.3 & 335 & 355 & 360 & 365 & .5477 & .5413 \\
\hline & 600 & -- & 1496.8 & 1495.1 & - & 45.9 & 46.8 & - & - & 592 & 590 & -- & .7745 \\
\hline \multirow{3}{*}{10} & 200 & 10.9 & 11.2 & 10.8 & 64.5 & 64.5 & 65.9 & 141 & 156 & 155 & 153 & .2739 & .2619 \\
\hline & 400 & 235.4 & 232.1 & 237.0 & 58.7 & 58.6 & 58.2 & 301 & 340 & 345 & 345 & .5163 & .5156 \\
\hline & 600 & -- & 1438.8 & 1441.1 & -- & 49.6 & 50.4 & -- & - & 567 & 557 & - & .7319 \\
\hline \multirow{3}{*}{15} & 200 & 10.4 & 10.2 & 10.3 & 67.0 & 66.5 & 67.9 & 132 & 151 & 148 & 150 & .2659 & .2569 \\
\hline & 400 & 221.7 & 221.9 & 221.7 & 61.3 & 61.1 & 60.9 & 277 & 322 & 330 & 331 & .4950 & .4954 \\
\hline & 600 & -- & 1373.5 & 1379.4 & -- & 53.2 & 54.0 & - & - & 541 & 525 & -- & .6959 \\
\hline \multirow{3}{*}{20} & 200 & 9.8 & 10.2 & 9.8 & 69.5 & 69.1 & 69.8 & 126 & 147 & 141 & 745 & .2582 & .2505 \\
\hline & 400 & 210.8 & 210.3 & 209.5 & 63.8 & 63.7 & 63.4 & 265 & 312 & 315 & 315 & .4758 & .4761 \\
\hline & 600 & - & 1303.9 & 1306.8 & - & 56.8 & 57.0 & -- & -- & 516 & 499 & - & .6638 \\
\hline \multirow{3}{*}{25} & 200 & 9.3 & 9.7 & 9.2 & 72.0 & 71.6 & 71.8 & 124 & 142 & 134 & 140 & .2511 & .2452 \\
\hline & 400 & 198.1 & 197.3 & 196.4 & 66.6 & 66.1 & 65.8 & 256 & 300 & 300 & 303 & .4591 & .4599 \\
\hline & 600 & $-\cdot$ & 1232.8 & 1225.1 & - & 60.2 & 59.9 & -- & -- & 491 & 476 & $\ldots$ & .6369 \\
\hline
\end{tabular}




\section{References}

1. Austin, A. L., Higgins, G. H., Howard, J. H., "The Total Flow Concept for Recovery of Energy From Geothermal Hot Brine Deposits", April 3, 1973, UCRL-51366, Lawrence Livermore Laboratory, Livermore, California.

2. Report DRI No. 2151, University of Denver-Denver Research Institute, "Determination of Themodynamic Properties of Brines", February 1964.

3. Haas, J. L. Jr., "The Effect of Salinity on the Maximum Thermal Gradient of a Hydrothermal System at Hydrostatic Pressure", Economic Geology, Vol. 66, 1971, pp. 940-946.

4. Daley, J. G., Hilding, W. E., Fisher, D. A. "Therniodynamic Properties of Seawater Concentrates", Proceedings 5th Symposium on Thermophysical Properties, October 1970.

5. Grens, J. Z., "The Effect of Salinity on Geothermal Well Performance", UCID-16791, May 14, 1975.

6. Discussions with R. W. Potter on February 22, 1977. Work to be published short7y.

7. Miller, I. and Freund, J. E., "Probability and Statistics for Engineers", Englewood Cliffs, N. J.: Prentice-Ha11, 1965.

8. McClintock, R. B. and Silvestri, G. J., "Calculation of Properties of Steam", American Society of Mechanical Engineers, 1968. 


\section{Appendix}

Table A1 - Brine Saturation Pressure Coefficients

Linear Curve-Fit Analysis

Table A2 - Linear Curve-Fit Regression Coefficients

Power Law Curve-Fit Analys is

Table A3 - Power Law Curve-Fit Refression Coefficients

Table A4 - Calculated Brine Entropy 
TABLE A1

BRINE SATURATION PRESSURE COEFFICIENTS FROM DATA IN REFERENCE 3

\begin{tabular}{|c|c|c|c|c|c|c|c|c|c|c|c|}
\hline & & \multicolumn{10}{|c|}{ WEIGHT PERCENT NaC1 } \\
\hline & & \multicolumn{2}{|c|}{5} & \multicolumn{2}{|c|}{10} & \multicolumn{2}{|c|}{15} & \multicolumn{2}{|c|}{20} & \multicolumn{2}{|c|}{25} \\
\hline$T$, & $\operatorname{PSAT}(T)$ & $\operatorname{PSATB}(T)$ & $\operatorname{PSATB}(T)$ & $\operatorname{PSATB}(T)$ & $\operatorname{PSATB}(T)$ & $\operatorname{PSATB}(T)$ & $\operatorname{PSATB}(T)$ & $\operatorname{PSATB}(T)$ & $\operatorname{PSATB}(T)$ & $\operatorname{PSATB}(T)$ & $\operatorname{PSATB}(T)$ \\
\hline${ }^{\circ} \mathrm{F}$ & BARS & BARS & $\operatorname{PSAT}(T)$ & BARS & $\operatorname{PSAT}(T)$ & BARS & $\overline{\operatorname{PSAT}(T)}$ & BARS & $\overline{\operatorname{PSAT}(T)}$ & BARS & $\operatorname{PSAT}(\mathrm{T})$ \\
\hline 230 & 1.4 & 1.4 & 1.0 & 1.3 & .929 & 1.3 & .929 & 1.2 & .857 & 1.1 & .786 \\
\hline 248 & 2.0 & 1.9 & .950 & 1.9 & .950 & 1.8 & .900 & 1.7 & .850 & 1.6 & .800 \\
\hline 266 & 2.7 & 2.6 & .963 & 2.5 & .926 & 2.4 & .889 & 2.3 & .852 & 2.1 & .773 \\
\hline 284 & 3.6 & 3.5 & .972 & 3.4 & .944 & 3.2 & .889 & 3.1 & .861 & 2.9 & .806 \\
\hline 302 & 4.8 & 4.6 & .958 & 4.4 & .917 & 4.3 & .896 & 4.0 & .833 & 3.8 & .792 \\
\hline 320 & 6.2 & 6.0 & .968 & 5.8 & .935 & 5.5 & .887 & 5.2 & .839 & 4.9 & .790 \\
\hline 338 & 7.9 & 7.7 & .975 & 7.4 & .937 & 7.1 & .899 & 6.7 & .848 & 6.3 & .797 \\
\hline 356 & 10.0 & 9.7 & .970 & 9.4 & .940 & 9.0 & .900 & 8.5 & .850 & 8.0 & .800 \\
\hline 374 & 12.6 & 12.2 & .968 & 11.7 & .929 & 11.2 & .889 & 10.6 & .841 & 10.0 & .794 \\
\hline 392 & 15.6 & 15.1 & .968 & 14.5 & .929 & 13.9 & .891 & 13.2 & .846 & 12.4 & .795 \\
\hline 410 & 19.1 & 18.5 & .969 & 17.8 & .932 & 17.0 & .890 & 16.2 & .848 & 15.2 & .796 \\
\hline 428 & 23.2 & 22.5 & .970 & 21.7 & .935 & 20.7 & .892 & 19.7 & .849 & 18.5 & .797 \\
\hline 446 & 28.0 & 27.1 & .968 & 26.1 & .932 & 25.0 & .893 & 23.7 & .846 & 22.3 & .796 \\
\hline 464 & 33.5 & 32.5 & .970 & 31.2 & .931 & 29.9 & .893 & 28.4 & .848 & 26.7 & .797 \\
\hline 482 & 39.8 & 38.6 & .970 & 37.1 & .932 & 35.5 & .892 & 33.7 & .847 & 31.8 & .799 \\
\hline 500 & 46.9 & 45.5 & .970 & 43.8 & .934 & 41.9 & .893 & 39.7 & .846 & 37.5 & .780 \\
\hline 518 & 55.1 & 53.3 & .967 & 51.3 & .931 & 49.7 & 891 & 46.6 & .846 & 44.0 & .799 \\
\hline 536 & 64.2 & 62.2 & .969 & 59.9 & .933 & 57.2 & .891 & 54.3 & .846 & 51.3 & .799 \\
\hline 554 & 74.4 & 72.1 & .969 & 69.4 & .933 & 66.3 & 891 & 62.9 & .845 & 59.5 & .780 \\
\hline 572 & 85.9 & 83.2 & .969 & 80.0 & .931 & 76.5 & .891 & 72.6 & .845 & 68.6 & .799 \\
\hline 590 & 98.7 & 95.6 & .969 & 91.9 & .931 & 87.8 & .890 & 83.3 & .844 & 78.7 & .797 \\
\hline 608 & 112.9 & 109.3 & .968 & 105.1 & .931 & 100.3 & .888 & 95.2 & .843 & 90.0 & .797 \\
\hline 626 & $\lcm{128.6}$ & 124.5 & .968 & 119.1 & 926 & 114.2 & .888 & 108.4 & .843 & 102.4 & .796 \\
\hline & & $a_{1}=$ & .969 & $a_{1}=$ & .934 & $a_{1}=$ & .894 & $a_{1}=$ & .847 & $a_{1}=$ & .794 \\
\hline
\end{tabular}




\section{Linear Curve-Fit Analysis (7)}

Assuming the relationship, $\operatorname{RHOB}(T)=\mathrm{a}_{2} \times T+\mathrm{a}_{3}$

Let $y=R H O B(T)$

$x=T$

$\therefore y=a_{2}(x)+a_{3}$

Using paired data from Reference 3,

$$
\left(x_{i}, Y_{i}\right), i=1,2, \ldots n
$$

with all summations for $i=1,2, \ldots n$.

Regression Coefficients

$$
\begin{aligned}
& a_{2}=\frac{\sum_{n} x_{i} Y_{i}-\frac{\sum_{n} x_{i} \sum_{n} y_{i}}{n}}{\sum_{n} x_{i}^{2}-\frac{\left(\sum_{n} x_{i}\right)^{2}}{n}} \\
& a_{3}=\bar{y}-a_{2}(\bar{x}) \\
& \bar{y}=\frac{\sum_{n} y_{i}}{n} \\
& \bar{x}=\frac{\sum_{n} x_{i}}{n}
\end{aligned}
$$

Coefficient of Determination

$$
r^{2}=\frac{\left[\sum_{n} x_{i} y_{i}-\frac{\sum_{n} x_{i} \sum_{n} y_{i}}{n}\right]^{2}}{\left[\sum_{n} x_{i}^{2}-\frac{\left(\sum_{n} x_{i}\right)^{2}}{n}\right]\left[\sum_{n} y_{i}^{2}-\frac{\left(\sum_{n} y_{i}\right)^{2}}{n}\right]}
$$


TABLE A2

LINEAR CURVE FIT

REGRESSION COEFFICIENTS FROM PAIRED DATA IN REFERENCE 3

BRINE DENSITY, LBM/FT ${ }^{3}$

\begin{tabular}{|c|c|c|c|c|c|}
\hline \multirow{2}{*}{$\mathrm{T},{ }^{\circ} \mathrm{F}$} & \multicolumn{5}{|c|}{ Weight Percent $\mathrm{NaCl}$} \\
\hline & 5 & 10 & 15 & 20 & 25 \\
\hline 230 & 61.53 & 63.77 & 66.08 & 68.45 & 70.95 \\
\hline 248 & 67.03 & 63.27 & 65.58 & 68.02 & 70.45 \\
\hline 266 & 60.53 & 62.84 & 65.15 & 67.52 & 70.01 \\
\hline 284 & 60.03 & 62.34 & 64.65 & 67.08 & 69.51 \\
\hline 302 & 59.47 & 61.78 & 64.15 & 66.58 & 69.01 \\
\hline 320 & 58.91 & 61.28 & 63.65 & 66.02 & 68.52 \\
\hline 338 & 58.34 & 60.72 & 63.09 & 65.52 & 67.95 \\
\hline 356 & 57.72 & 60.09 & 62.52 & 64.96 & 67.45 \\
\hline 374 & 57.10 & 59.53 & 61.96 & 64.46 & 66.89 \\
\hline 392 & 56.41 & 58.91 & 61.40 & 63.90 & 66.33 \\
\hline 410 & 55.72 & 58.28 & 60.78 & 63.34 & 65.83 \\
\hline 428 & 55.04 & 57.60 & 60.15 & 62.71 & 65.27 \\
\hline 446 & 54.29 & 56.91 & 59.53 & 62.15 & 64.71 \\
\hline 464 & 53.48 & 56.22 & 58.91 & 61.53 & 64.15 \\
\hline 482 & 52.67 & 55.47 & 58.22 & 60.96 & 63.59 \\
\hline 500 & 51.79 & 54.66 & 57.53 & 60.34 & 63.02 \\
\hline 518 & 50.92 & 53.85 & 56.78 & 59.72 & 62.52 \\
\hline 536 & 49.98 & 53.04 & 56.10 & 59.09 & 61.96 \\
\hline 554 & 48.92 & 52.10 & 55.35 & 58.47 & 61.46 \\
\hline 572 & 47.86 & 51.17 & 54.54 & 57.84 & 60.96 \\
\hline 590 & 46.68 & 50.17 & 53.73 & 57.16 & 60.47 \\
\hline 608 & 45.36 & 49.11 & 52.85 & 56.53 & 60.03 \\
\hline 626 & 43.93 & 47.92 & 51.92 & 55.91 & 59.53 \\
\hline$a_{3}=$ & 72.602 & 73.720 & 74.864 & 76.214 & 77.849 \\
\hline$a_{2}=$ & -0.043 & -0.039 & -0.035 & -0.032 & -0.030 \\
\hline$r^{2}=$ & .9793 & .9853 & .9921 & .9977 & .9996 \\
\hline
\end{tabular}


Power Law Curve-Fit Analys is

(7)

Assuming the relationship, $H B(T)=a_{4}(T)^{a_{5}}$

Let $y=H B(T)$

$$
\begin{aligned}
x & =T \\
y & =a_{4}(x)^{a_{5}}, a_{4}>0 \text { and } \\
\ln y & =a_{5} \ln x+\ln a_{4}, \text { which is a linear equation. }
\end{aligned}
$$

Using the set of data points in Reference 4

$$
\left\{\left(x_{i}, y_{i}\right), i=1,2 \ldots n\right\} \text {, where } x_{i}>0 \text { and } y_{i}>0 \text {, }
$$

$n$ is a positive integer and $n \neq 1$.

Regression Coefficients

$$
\begin{aligned}
& a_{5}=\frac{\sum_{n}\left(\ln x_{i}\right)\left(\ln y_{i}\right)-\frac{\left(\sum_{n} \ln x_{i}\right)\left(\sum_{n} \ln y_{i}\right)}{n}}{\left(\sum_{n} \ln x_{i}\right)^{2}-\frac{\left(\sum_{n} \ln x_{i}\right)^{2}}{n}} \\
& a_{4}=\exp \left[\frac{\sum_{n} \ln y_{i}}{n}-a_{5}\left(\frac{\sum \ln x_{i}}{n}\right)\right]
\end{aligned}
$$

\section{Coefficient of Determination}

$$
\begin{aligned}
& r^{2}=\left[\sum_{n}\left(\ln x_{i}\right)\left(\ln y_{i}\right)-\left(\sum_{n}^{\sum} \ln x_{i}\right)\left(\sum_{n} \ln y_{i}\right)\right]^{2} \\
& {\left[\sum_{n}\left(\ln x_{i}\right)^{2}-\frac{\left(\sum_{n} \ln x_{i}\right)^{2}}{n}\right]\left[\sum_{n}\left(\ln y_{i}\right)^{2}-\frac{\left(\sum_{n} \ln y_{i}\right)^{2}}{n}\right]}
\end{aligned}
$$


TABLE A3

POWER LAW CURVE FIT-REGRESSION CCEFFICIENTS FROM DATA IN REFERENCE 4

\begin{tabular}{|c|c|c|c|c|c|}
\hline \multirow{2}{*}{$\mathrm{T},{ }^{\mathrm{o}} \mathrm{F}$} & \multicolumn{5}{|c|}{ Weight Percent Salinity } \\
\hline & 5 & 10 & 15 & 20 & 25 \\
\hline 30 & 48.95 & 49.33 & 49.43 & 49.27 & 49.09 \\
\hline 90 & 58.32 & 53.18 & 57.90 & 57.39 & 56.90 \\
\hline 100 & 67.69 & 67.03 & 66.36 & 65.61 & 64.68 \\
\hline 110 & 77.06 & 75.88 & 74.83 & 73.61 & 72.47 \\
\hline 120 & 36.42 & 84.74 & 83.29 & 81.72 & 80.24 \\
\hline 130 & 95.79 & 93.61 & 91.76 & 39.82 & 88.02 \\
\hline 140 & 105.16 & 102.48 & 100.23 & 97.92 & 95.79 \\
\hline 150 & 114.53 & 111.37 & 108.70 & 106.01 & 103.54 \\
\hline 160 & 123.19 & 120.26 & 117.17 & 114.11 & 171.31 \\
\hline 170 & 133.30 & 129.16 & 125.65 & 122.20 & 179.06 \\
\hline 180 & 142.69 & 738.08 & 134.14 & 730.30 & 126.31 \\
\hline 190 & 152.09 & 147.01 & 142.63 & 138.40 & 134.57 \\
\hline 200 & 161.51 & 155.95 & 151.13 & 146.51 & 142.32 \\
\hline 210 & 170.93 & 164.91 & 159.64 & 154.62 & 150.10 \\
\hline 220 & 180.38 & 173.89 & 168.16 & 162.74 & 156.85 \\
\hline 230 & 189.83 & 182.89 & 176.70 & 170.87 & 165.64 \\
\hline 240 & 199.31 & 191.90 & 185.25 & 179.01 & 173.42 \\
\hline 250 & 208.80 & 200.94 & 193.81 & 137.16 & 181.21 \\
\hline 260 & 218.32 & 210.00 & 202.39 & 195.32 & 189.01 \\
\hline 270 & 227.85 & 219.08 & 210.99 & 203.49 & 196.83 \\
\hline 280 & 237.42 & 228.19 & 279.60 & 271.68 & 204.66 \\
\hline 290 & 247.00 & 237.32 & 228.24 & 219.89 & 212.50 \\
\hline 300 & 256.61 & 246.48 & 236.90 & 228.11 & 220.35 \\
\hline 370 & 266.25 & 255.67 & 245.57 & 236.35 & 228.23 \\
\hline 320 & 275.91 & 264.89 & 254.28 & 244.61 & 236.12 \\
\hline 330 & 285.67 & 274.13 & 263.01 & 252.89 & 244.02 \\
\hline 340 & 295.35 & 283.42 & 271.76 & 261.20 & 251.97 \\
\hline 350 & 305.12 & 292.73 & 280.54 & 269.52 & 250.91 \\
\hline 360 & 314.92 & 302.08 & 289.35 & 277.88 & 267.89 \\
\hline 370 & 324.75 & 311.46 & 298.19 & 286.25 & 275.88 \\
\hline 380 & 334.63 & 320.88 & 307.06 & 294.66 & 283.91 \\
\hline $\begin{array}{l}390 \\
400\end{array}$ & $\begin{array}{l}344.55 \\
354.51\end{array}$ & $\begin{array}{l}330.34 \\
339.84\end{array}$ & $\begin{array}{l}315.96 \\
322.20\end{array}$ & $\begin{array}{l}303.09 \\
311.56\end{array}$ & $\begin{array}{l}291.97 \\
300.04\end{array}$ \\
\hline$a_{4}=$ & .2745 & .3040 & .3398 & .3682 & .3957 \\
\hline$a_{5}=$ & 1.1996 & 1.1746 & 1.1480 & 1.1274 & 1.1087 \\
\hline$r^{2}=$ & .9985 & .9990 & .9992 & .9994 & .9995 \\
\hline 500 & 474.44 & 449.86 & 426.25 & 406.28 & 388.64 \\
\hline 600 & 590.42 & 557.29 & 525.49 & 498.98 & 475.70 \\
\hline
\end{tabular}


TABLE A4

CALCULATED BRINE ENTROPY, BTU/LBM ${ }^{\circ} R$

\begin{tabular}{|c|c|c|c|c|c|}
\hline & \multicolumn{5}{|c|}{ Weight Percent Salinity } \\
\hline & 5 & 10 & 15 & 20 & 25 \\
\hline & $\begin{array}{l}a_{1}=.969 \\
a_{2}=.043 \\
a_{3}=72.6 \\
a_{4}=.275 \\
a_{5}=1.1996 \\
\alpha=2.469 \times 10^{-3} \\
\beta=5.923 \times 10^{-4}\end{array}$ & $\begin{array}{l}a_{1}=.934 \\
a_{2}=.039 \\
a_{3}=73.72 \\
a_{4}=.304 \\
a_{5}=1.1746 \\
\alpha=2.344 \times 10^{-3} \\
\beta=5.29 \times 10^{-4}\end{array}$ & $\begin{array}{l}a_{1}=.894 \\
a_{2}=.035 \\
a_{3}=74.86 \\
a_{4}=.340 \\
a_{5}=1.1480 \\
\alpha=2.209 \times 10^{-3} \\
B=4.675 \times 10^{-4}\end{array}$ & $\begin{array}{l}a_{1}=.847 \\
a_{2}=.032 \\
a_{3}=76.21 \\
a_{4}=.363 \\
a_{5}=1.1274 \\
\alpha=2.056 \times 10^{-3} \\
B=4.199 \times 10^{-4}\end{array}$ & $\begin{array}{l}a_{1}=.794 \\
a_{2}=.030 \\
a_{3}=77.85 \\
a_{4}=.396 \\
a_{5}=1.1087 \\
\alpha=1.887 \times 10^{-3} \\
\beta=3.854 \times 10^{-4}\end{array}$ \\
\hline $80^{(4)}$ & .0949 & .0956 & .0958 & .0955 & .0951 \\
\hline 100 & .7246 & .1236 & .1227 & .1219 & .1211 \\
\hline 120 & .1541 & .1521 & .1502 & .1484 & .1468 \\
\hline 140 & .1837 & .1795 & .1774 & .1745 & .1721 \\
\hline 160 & .2131 & .2066 & .2043 & .2003 & .1969 \\
\hline 180 & .2423 & .2344 & .2308 & .2256 & .2213 \\
\hline 200 & .2712 & .2619 & .2569 & .2505 & .2452 \\
\hline 220 & .2998 & .2890 & .2826 & .2750 & .2686 \\
\hline 240 & .3281 & .3157 & .3078 & .2990 & .2916 \\
\hline 260 & .3560 & .3421 & .3327 & .3226 & .3141 \\
\hline 280 & .3836 & .3680 & .3572 & .3458 & .3362 \\
\hline 300 & .4108 & .3936 & .3812 & .3685 & .3578 \\
\hline 320 & .4377 & .4188 & .4048 & .3908 & .3790 \\
\hline 340 & .4642 & .4436 & .4281 & .4127 & .3998 \\
\hline 360 & .4903 & .4680 & .4509 & .4342 & .4202 \\
\hline 380 & .5160 & .4920 & .4733 & .4554 & .4403 \\
\hline 400 & .5413 & .5156 & .4954 & .4761 & .4599 \\
\hline 420 & .5663 & .5389 & .5170 & .4965 & .4791 \\
\hline 440 & .5909 & .5618 & .5383 & .5164 & .4980 \\
\hline 460 & .6151 & .5843 & .5593 & .5361 & .5166 \\
\hline 480 & .6390 & .6065 & .5799 & .5553 & .5348 \\
\hline 500 & .6625 & .6283 & .6001 & .5743 & .5526 \\
\hline 520 & .6857 & .6497 & 6199 & .5928 & .5701 \\
\hline 540 & .7084 & .6708 & .6394 & .6111 & .5873 \\
\hline 560 & .7308 & .6915 & .6586 & .6290 & .6042 \\
\hline 580 & .7529 & .7119 & .6774 & .6466 & .6207 \\
\hline 600 & .7745 & .7379 & .6959 & .6638 & .6369 \\
\hline
\end{tabular}


NOTICE

This report was prepared as an account of work sponsored by the United States Government. Neither the United States nor the United States Energy Research \& Developinent Administration, nor any of their employees, nor any of their contractors, subcontractors, or their employees, makes any warranty, express or implied, or assumes any legal liability or responsibility for the accuracy, completeness or usefulness of any information, apparatus, product or process disclosed, or represents that its use would not infringe privately-ow ned rights.

NOTICE

Reference to a company or product name does not imply approval or recommendation of the product by the University of California or the U.S. Energy Research \& Development Administration to the exclusion of others that may be suitable:

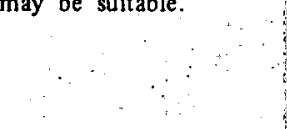

Printed in the United States of America Aỵailable from

National Technical Information Service

U.S. Department of Commerce

5285 ' Port Royal Road

Springfield, VA 2216

Price Printed Copy

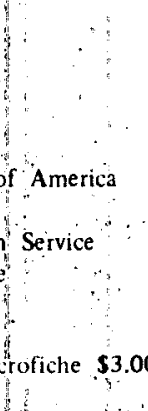



*Add $\$ 2.50$ for each additional 100 page increment from 601 to 1,000 pages: add $\$ 4.50$ for each additional 100 page increment over 1,000 pages. 